\title{
Measurement of Upper Limb Range of Motion Using Wearable Sensors: A Systematic Review
}

\author{
Corrin P. Walmsley ${ }^{1} \mathbb{D}$, Sîan A. Williams ${ }^{2,3} \mathbb{B}$, Tiffany Grisbrook ${ }^{2} \mathbb{D}$, Catherine Elliott ${ }^{1,4} \mathbb{D}$, Christine $\mathrm{mms}^{5^{*}}$ (D)
} and Amity Campbell ${ }^{2}$

\begin{abstract}
Background: Wearable sensors are portable measurement tools that are becoming increasingly popular for the measurement of joint angle in the upper limb. With many brands emerging on the market, each with variations in hardware and protocols, evidence to inform selection and application is needed. Therefore, the objectives of this review were related to the use of wearable sensors to calculate upper limb joint angle. We aimed to describe (i) the characteristics of commercial and custom wearable sensors, (ii) the populations for whom researchers have adopted wearable sensors, and (iii) their established psychometric properties.
\end{abstract}

Methods: A systematic review of literature was undertaken using the following data bases: MEDLINE, EMBASE, CINAHL, Web of Science, SPORTDiscus, IEEE, and Scopus. Studies were eligible if they met the following criteria: (i) involved humans and/or robotic devices, (ii) involved the application or simulation of wearable sensors on the upper limb, and (iii) calculated a joint angle.

Results: Of 2191 records identified, 66 met the inclusion criteria. Eight studies compared wearable sensors to a robotic device and 22 studies compared to a motion analysis system. Commercial ( $n=13)$ and custom $(n=7)$ wearable sensors were identified, each with variations in placement, calibration methods, and fusion algorithms, which were demonstrated to influence accuracy.

Conclusion: Wearable sensors have potential as viable instruments for measurement of joint angle in the upper limb during active movement. Currently, customised application (i.e. calibration and angle calculation methods) is required to achieve sufficient accuracy (error $<5^{\circ}$ ). Additional research and standardisation is required to guide clinical application.

Trial Registration: This systematic review was registered with PROSPERO (CRD42017059935).

Keywords: Kinematics, Wearable sensor, Inertial movement unit, Joint angle, Motion analysis, Upper limb

\section{Key Points}

- Both commercially available and custom wearable sensors have some evidence of validity in the literature. Although commercial wearable sensors were validated against pseudo gold standards, each study customised the commercial software to do so.

\footnotetext{
* Correspondence: Christine.Imms@acu.edu.au

${ }^{5}$ Centre for Disability and Development Research, School of Allied Health,

Australian Catholic University, Melbourne, VIC 3065, Australia

Full list of author information is available at the end of the article
}

- Wearable sensors demonstrated errors $<5^{\circ}$ for all degrees of freedom at the wrist and elbow joints when compared to a robotic device. The range in error is greater when measured in vivo and compared to a pseudo gold standard.

- The measured errors are within margins that warrant future use of wearable sensors to measure joint angle in the upper limb.

\section{Background}

Clinicians and researchers seek information about the quality and quantity of patients' movement as it provides 
useful information to guide and evaluate intervention. Range of motion (ROM), defined as rotation about a joint, is measured in a variety of clinical populations including those with orthopaedic, musculoskeletal, and neurological disorders. Measurement of ROM forms a valuable part of clinical assessment; therefore, it is essential that it is completed in a way that provides accurate and reliable results $[1,2]$.

In clinical practice, the goniometer is a widely used instrument to measure ROM [2-4]. Despite being considered a simple, versatile, and an easy-to-use instrument, reports of reliability and accuracy are varied. Intra-class correlation coefficients (ICCs) range from 0.76 to 0.94 (intra-rater) [3, 4] and 0.36 to 0.91 (inter-rater) [4] for shoulder and elbow ROM. Low inter-rater reliability is thought to result from the complexity and characteristics of the movement, the anatomical joint being measured, and the level of assessor experience [5, 6]. The goniometer is also limited to measuring joint angles in single planes and static positions; thus, critical information regarding joint angles during dynamic movement cannot be measured.

In research settings, three-dimensional motion analysis (3DMA) systems, such as Vicon (Vicon Motion Systems Ltd., Oxford, UK) and Optitrack (NaturalPoint, Inc., Corvallis, OR, USA), are used to measure joint angles during dynamic movement in multiple degrees of freedom (DOF). Such systems are considered the gold standard' for evaluating lower limb kinematics, with a systematic review reporting errors $<4.0^{\circ}$ for movement in the sagittal plane and $<2.0^{\circ}$ in the coronal plane; higher values have been reported for hip rotation in the transverse plane (range 16 to $34^{\circ}$ ) [7]. Measurement in the upper limb is considered more technically challenging due to the complexity of shoulder, elbow, and wrist movements [8]. However, given the demonstrated accuracy in the lower limb, 3DMA systems are used as the 'ground truth' when validating new upper limb measurement tools [9]. However, 3DMA does have limitations. Most notably, these systems are typically immobile, expensive, require considerable expertise to operate, and therefore rarely viable for use with clinical populations $[10,11]$.

Wearable sensors, or inertial measurement units, are becoming increasingly popular for the measurement of joint angle in the upper limb [12]. In this review, we were interested in wearable sensors that contained accelerometers and gyroscopes, with or without a magnetometer, to indirectly derive orientation. The software typically utilised three main steps: (i) calibration, using two approaches: (1) system, also referred to as 'factory calibration' (offset of the hardware on a flat surface), and (2) anatomical calibration including both static (pre-determined pose) and dynamic (pre-determined movement) [10, 13]; (ii) filtering, using fusion algorithms including variations of the Kalman filter (KF) $[14,15]$; and (iii) segment and angle definition, using Euler angle decompositions and/or Denavit-Hartenberg Cartesian coordinates.

Wearable sensors are an increasingly popular surrogate for laboratory-based 3DMA due to their usability, portability, size, and cost. Systematic reviews have detailed their use during swimming [16] and whole body analysis [17] and in the detection of gait parameters and lower limb biomechanics [18]. However, their validity and reliability must be established and acceptable prior to their application [19]. Accuracy of the wearable sensors is dependent on the joint and movement being measured; therefore, a systematic review specific to the upper limb is required. This study aimed to establish the evidence for the use of wearable sensors to calculate joint angle in the upper limb, specifically:

i. What are the characteristics of commercially available and custom designed wearable sensors?

ii. What populations are researchers applying wearable sensors for and how have they been used?

iii. What are the established psychometric properties for the wearable sensors?

\section{Methods}

This systematic review was conducted in accordance with the Preferred Reporting Items for Systematic Reviews and Meta-Analyses guidelines [20] and registered with the International Prospective Register of Systematic Reviews on 23 March 2017 (CRD42017059935).

\section{Search Terms and Data Bases}

Studies and conference proceedings were identified through searches in scientific data bases relevant to the fields of biomechanics, medicine, and engineering, from their earliest records to November 1, 2016: MEDLINE via PROQUEST, EMBASE via OVID, CINAHL via EBSCO, Web of Science, SPORTDiscus, IEEE, and Scopus. Reference lists were searched to ensure additional relevant studies were identified. The search was updated on 9 October 2017 to identify new studies that met the inclusion criteria.

The following search term combinations were used: ("wearable sens" ${ }^{*}$ "OR "inertial motion unit" " OR "inertial movement unit" OR "inertial sens" ("movement" analysis" OR "motion analysis" OR "motion track" OR "track" motion*" OR "measurement system"*" OR movement) AND ("joint angle" OR angle OR kinematic" OR "range of motion") AND ("upper limb" OR "upper extremit" OR arm* OR elbow* OR wrist* OR shoulder* OR humerus*). Relevant MeSH terms were included where appropriate, and searches were limited to title, abstract, and key words. All 

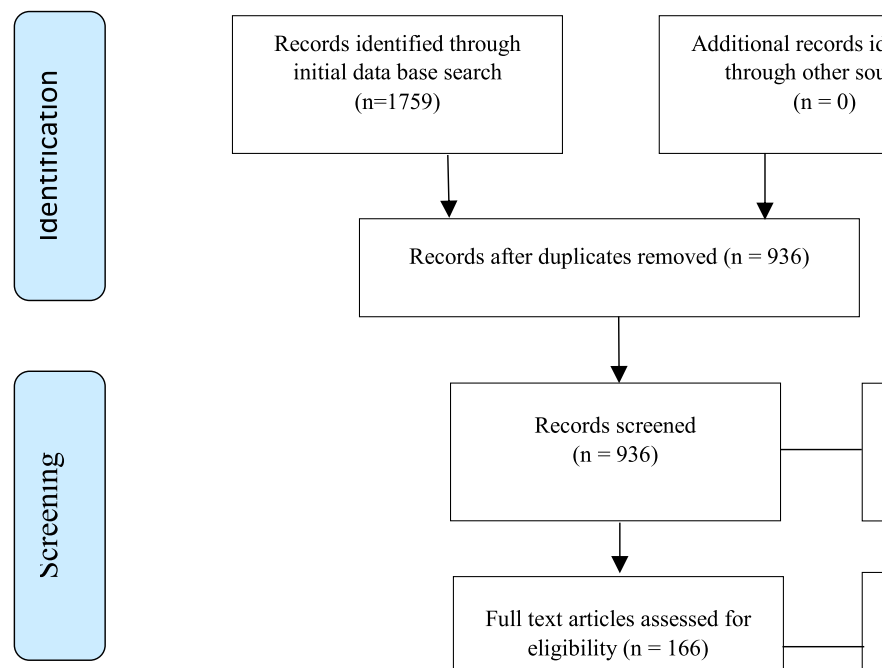

Records excluded $(\mathrm{n}=770)$

Full text articles assessed for eligibility $(n=166)$

Full text articles excluded with reasons $(n=115)$

Did not measure joint angle $(n=48)$

Different motion tracking system $(\mathrm{n}=33)$

Did not include the upper limb $(\mathrm{n}=3)$

Used one single inertial sensor $(n=13)$

Not published in English $(n=4)$

Poster/presentation abstracts without full text $(n=4)$

Book chapter $(\mathrm{n}=1)$

Literature review $(\mathrm{n}=1)$

Duplicate $(\mathrm{n}=5)$

Conference abstracts with no full text after contacting the author $(n=3)$

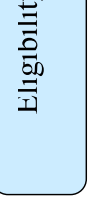

Conference abstracts with no full text after contacting the author $(\mathrm{n}=3)$

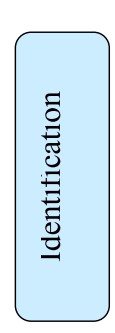

Studies included in narrative synthesis $(\mathrm{n}=51)$
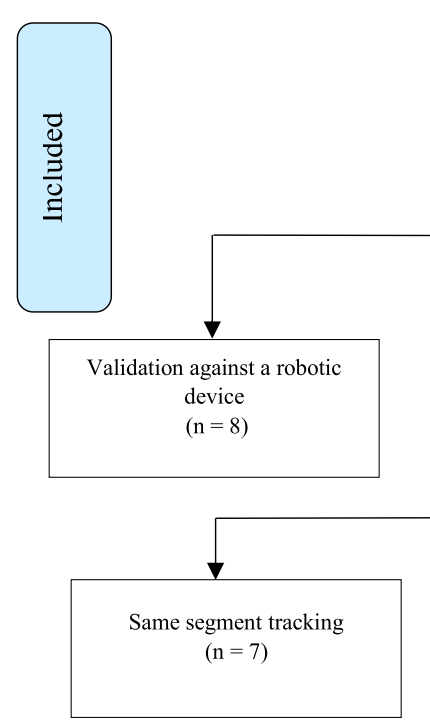

Fig. 1 A PRISMA diagram of the search strategy 
references were imported into Endnote X6 (Thomson Reuters, Carlsbad, CA, USA), and duplicates were removed.

\section{Study Selection Criteria and Data Extraction}

The title and abstracts were screened independently by two reviewers $(\mathrm{CW}$ and $\mathrm{AC})$. Full texts were retrieved if they met the inclusion criteria: (i) included human participants and/or robotic devices, (ii) applied/simulated use of wearable sensors on the upper limb, and (iii) calculated an upper limb joint angle. The manuals of commercial wearable sensors were located, with information extracted when characteristics were not reported by study authors. Studies were excluded based on the following criteria: (i) used a single wearable sensor, (ii) included different motion analysis systems (i.e. WiiMove, Kinetic, and smart phones), (iii) used only an accelerometer, (iv) calculated segment angle or position, (v) studied the scapula, or (vi) were not published in English.

Two reviewers (CW and $\mathrm{AC}$ ) extracted data independently to a customised extraction form. Discrepancies were discussed, and a third reviewer (TG) was involved when consensus was not reached. Extracted parameters of the wearable sensor characteristics included custom and commercial brands, the dimensions (i.e. height and weight), components used (i.e. accelerometer, gyroscope, and magnetometer), and the sampling rate (measured in hertz $(\mathrm{Hz}))$. Sample characteristics included the number of participants, their age, and any known clinical pathology. To determine if authors of the included studies customised aspects of the wearable sensors system, the following parameters were extracted: the type of calibration (i.e. system and anatomical), the fusion algorithms utilised, how anatomical segments were defined, and how joint angle was calculated.

To understand the validity and reliability of the wearable sensors, information about the comparison system, marker placement, and psychometric properties were extracted. The mean error, standard deviation (SD), and root mean square error (RMSE) reported in degrees were extracted where possible from the validation studies. The RMSE represents the error or difference between the wearable sensor and the comparison system (e.g. 3DMA system). The larger the RMSE, the greater the difference (in degrees) between the two systems. Further, to report on the validity of the wearable sensors, studies that did not delineate error between the wearable sensor and soft tissue artefact (movement of the markers with the skin) by not using the same segment tracking were not further analysed. Reliability was assessed using ICCs, with values $<0.60$ reflecting poor agreement, $0.60-0.79$ reflecting adequate agreement, and $0.80-1.00$ reflecting excellent agreement [21].
The following parameters were used to guide the interpretation of measurement error, with $<2.0^{\circ}$ considered acceptable, between 2.0 and $5.0^{\circ}$ regarded as reasonable but may require consideration when interpreting the data, and $>5.0^{\circ}$ of error was interpreted with caution [7].

\section{Assessment of Risk of Bias and Level of Evidence}

Due to the variability between research disciplines (i.e. health and engineering) in the way that studies were reported, and the level of detail provided about the research procedures, the available assessments of risk of bias and levels of evidence were not suitable for this review. Therefore, the following criteria were used to evaluate the quality of the reporting in the included studies:

- The aim of the study was clear and corresponded to the results that were reported.

- The study design and type of paper (i.e. conference proceeding) were considered.

- Number of participants included in the study was considered in relation to the COSMIN guidelines which indicate that adequate samples require 50-99 participants [19].

\section{Results}

The initial search (2016) identified 1759 studies eligible for inclusion, with an additional 432 studies identified 12 months later (2017). A total of 66 studies met the inclusion criteria (Fig. 1). Eight studies reported on the validation against a robotic device, and 22 reported on validation against a motion analysis system with human participants. One study assessed the reliability of the wearable sensors, with the remaining 35 studies using wearable sensors as an outcome measure in an experimental design.

\section{Characteristics and Placement of the Wearable Sensors}

The characteristics of the wearable sensors are summarised in Table 1. A total of seven customised wearable sensors and 13 commercial brands were identified. The level of detail provided for the placement of the wearable sensors on the upper limb varied significantly, as did the mode of attachment (Table 1).

\section{Calibration Methods}

Forty-seven studies reported on a calibration procedure prior to data acquisition. System calibration, also commonly known as 'factory calibration', was reported on 12 occasions, with two procedures described for the wearable sensors: (i) placement on a flat surface and/or (ii) movement in a pre-determined order while attached to a flat surface [56, 62]. The aim of system calibration was 


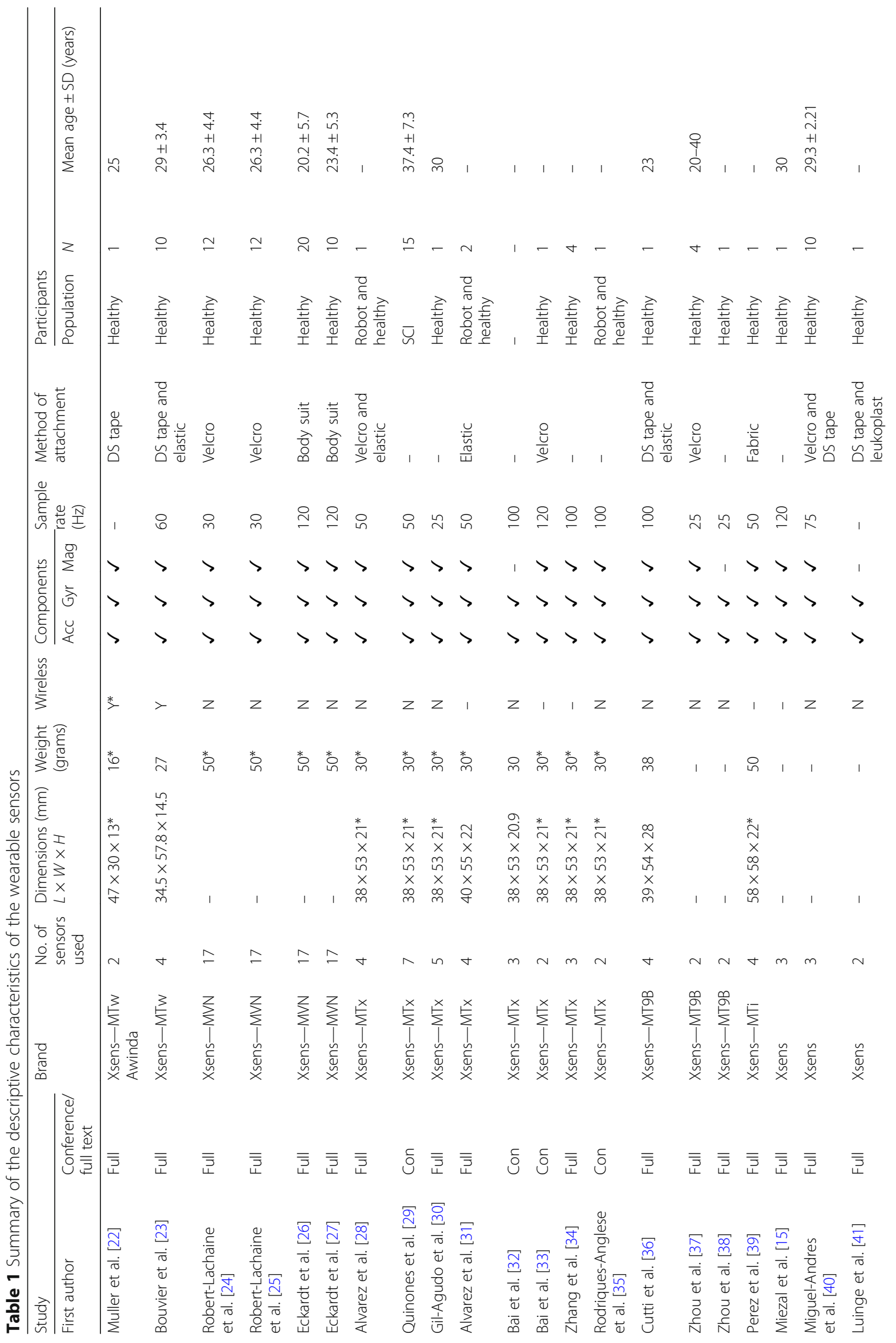




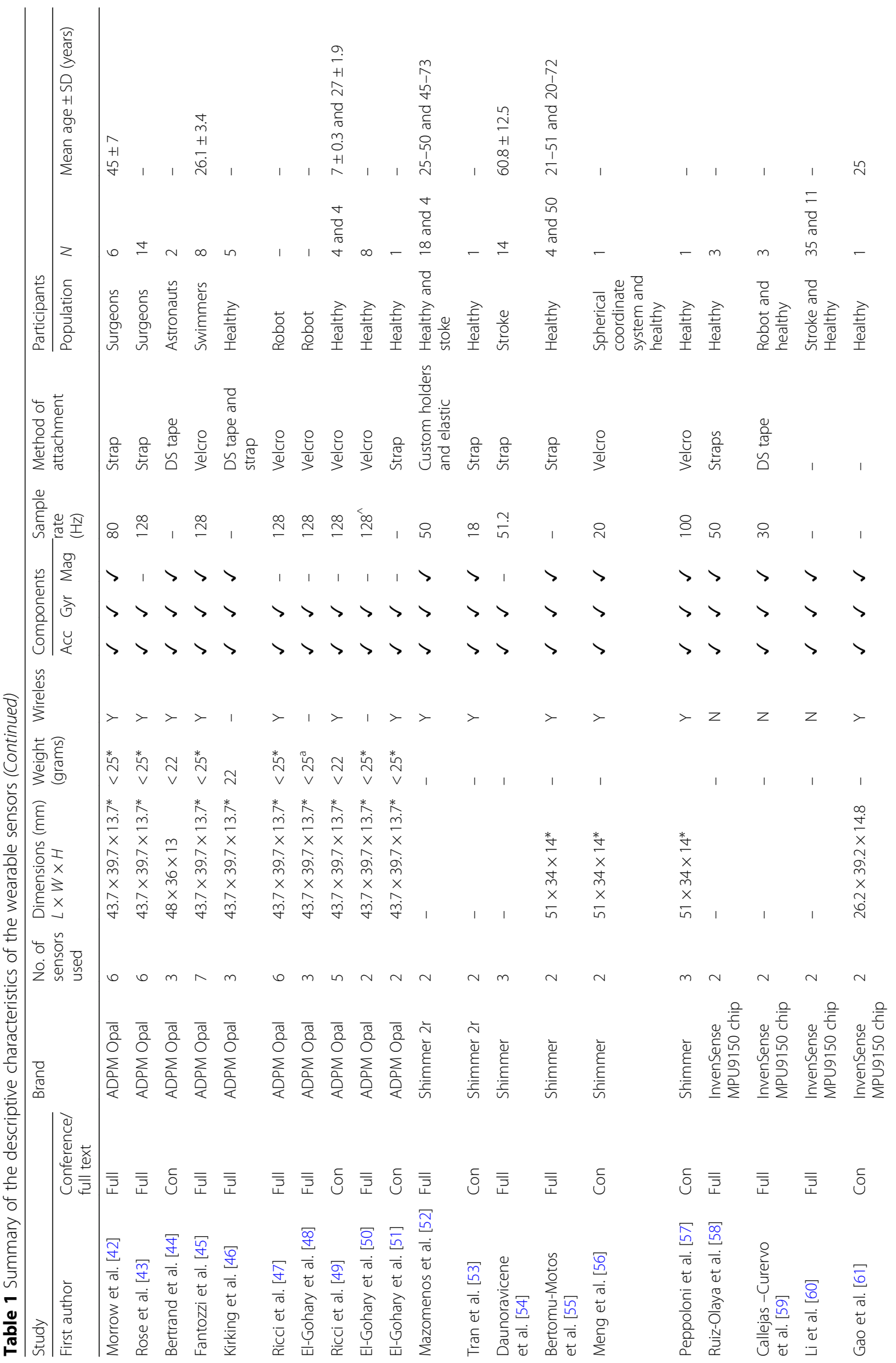




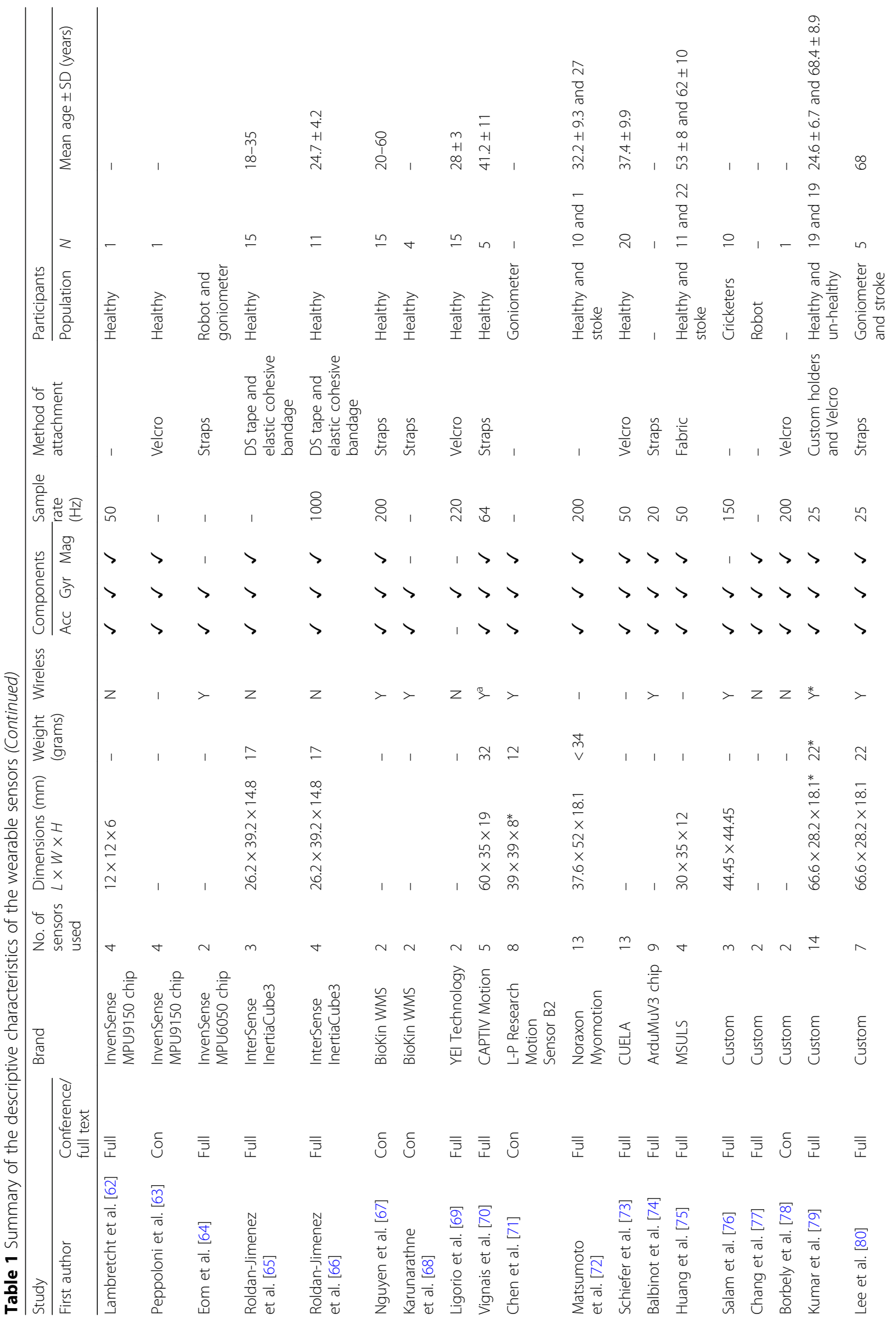




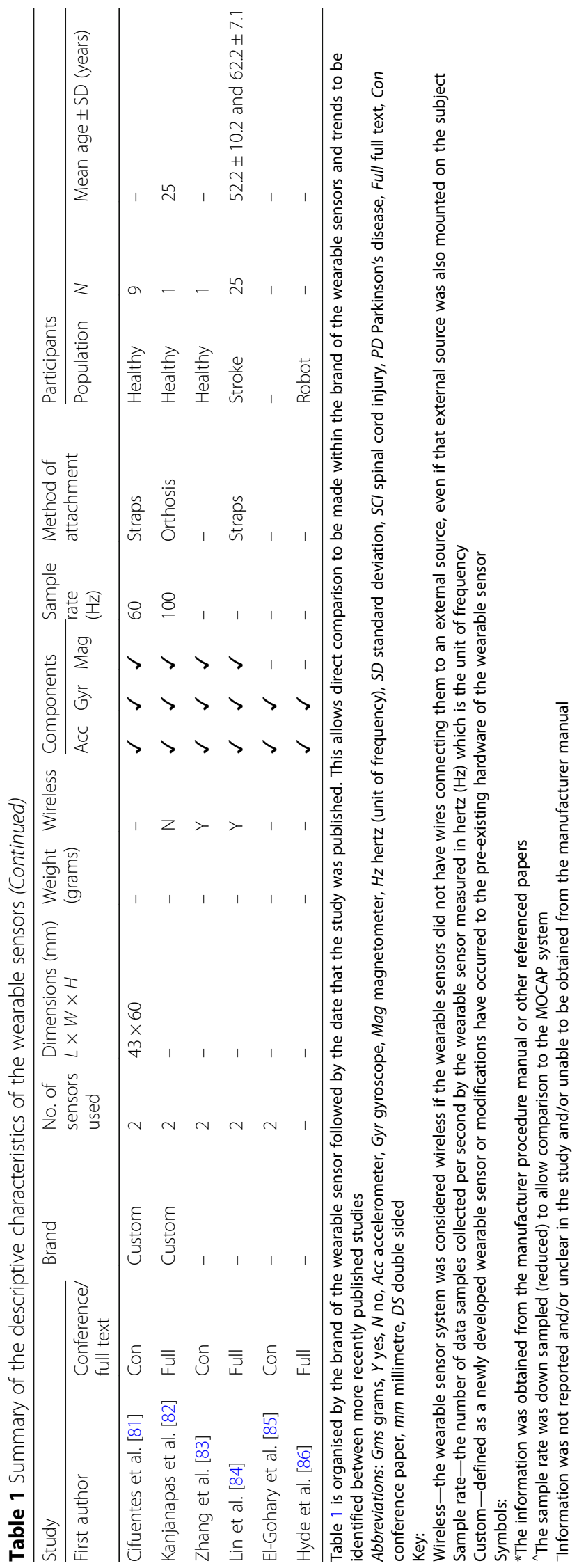


reported to be to align coordinate systems $[39,56]$ and account for inaccuracies in the orientation of wearable sensor chip relative to its case/packaging [62]. Static anatomical calibration was performed often $(n=34)$, with dynamic anatomical calibration performed sometimes $(n=10)$ [23, 30, 36, 41, 45, 49, 57]. Only one study used system calibration alongside both static and dynamic anatomical calibrations to compute joint kinematics [47].

\section{Populations Assessed Using Wearable Sensors}

Most studies $(n=52)$ recruited healthy adults; participants with known pathology were reported in nine studies (Table 1$)$. One study recruited children $(<18$ years) [49]. Sample sizes ranged from 1 to 54 participants, with a median sample of 7.6 participants per study. Twenty-nine studies recruited less than five participants, with 20 studies recruiting one single participant.

\section{Psychometric Properties of Wearable Sensors Validity}

Validation studies were split into two categories: (i) studies that compared the wearable sensor output to simulated upper limb movement on a robotic device (Table 2) and (ii) studies that compared wearable sensors output to a 3DMA system on a human participant (Table 3). The term 'error' is used to describe the difference between the capture systems; however, we acknowledge that comparisons between the wearable sensors and a robotic device are the only true measures of error.

\section{Robot Comparisons}

Eight studies reported the error of wearable sensors when compared to simulated upper limb movement on a robotic device (Table 2). A mean error between 0.06 and $1.8^{\circ}$ for flexion and 1.05 and $1.8^{\circ}$ for lateral deviation of the wrist was reported using Xsens [28, 31]. For elbow flexion/extension, the difference between Invensence and the robotic device was between 2.1 and 2.4 [59]. For finger flexion/extension, RMSEs ranged from 5.0 to $7.0^{\circ}$ using a customised wearable sensor system [77].

Three studies reported the error associated with the use of different fusion algorithms. Using the unscented Kalman filter (UKF) to fuse data from Opal wearable sensors, the RMSE range was $0.8-8.1^{\circ}$ for $2 \mathrm{DOF}$ at the shoulder, $0.9-2.8^{\circ}$ for $1 \mathrm{DOF}$ at the elbow, $1.1-3.9^{\circ}$ for $1 \mathrm{DOF}$ of the forearm, and $1.1-2.1^{\circ}$ for $2 \mathrm{DOF}$ at the wrist $[46,48]$. The rotation of the shoulder and twist of the wrist resulted in more error compared to single plane movements of flexion/extension and pronation/supination $[46,48]$. When the UKF was compared to a modified UKF, lower RMSEs were found across all 6DOF using the modified UKF [46]. One study investigated the effects that speed of movement had on measurement error. Using Opal wearable sensors, the UKF was compared to the extended Kalman filter (EKF) under three speed conditions: slow, medium, and fast. For slow movements, both fusion algorithms were comparable across all 6DOF (RMSE $0.8-7.8^{\circ}$ for the UKF and 0.8$8.8^{\circ}$ for the EKF). The UKF resulted in less error across 6DOF for the medium (RMSE 1.2-3.0 ${ }^{\circ}$ ) and fast (RMSE $1.1-5.9^{\circ}$ ) speeds compared to the EKF (RMSE 1.4-8.6 $\left.1.4-9.7^{\circ}\right)[48]$.

\section{DMA Comparisons}

Twenty-two studies compared the joint angles calculated by wearable sensors, both custom and commercial, to a 'gold standard' 3DMA system (Table 3). Studies that used same segment tracking (i.e. motion analysis markers directly on the wearable sensors) were reported in 7 studies. Opal wearable sensors were compared to a 3DMA system during simulated swimming (multiplane movement). The largest difference between the two systems occurred at the elbow (RMSE $6-15^{\circ}$ ), with the least occurring at the wrist (RMSE 3.0-5.0 $0^{\circ}$ [45]. Xsens was compared to codamotion during single plane movement, with the addition of a dynamic anatomical calibration trial [30]. The largest difference occurred at the elbow $\left(5.16^{\circ} \pm 4.5\right.$ to $\left.0.54^{\circ} \pm 2.63\right)$, and the least difference at the shoulder $\left(0.65^{\circ} \pm 5.67\right.$ to $\left.0.76^{\circ} \pm 4.40\right)$ [30]. Xsens was compared to Optotrak with consistent differences between systems across all DOFs of the shoulder (RMSE 2.5-3.0 $0^{\circ}$ ), elbow (RMSE $2.0-2.9^{\circ}$ ), and wrist (RMSE 2.8$\left.3.8^{\circ}\right)$ [24].

Three studies investigated the performance of wearable sensors using different fusion methods to amalgamate the data and compared this to a 'gold standard' system. Zhang and colleagues [34] compared the accuracy of their own algorithm to two pre-existing algorithms. Comparing Xsens to the BTS Optoelectronic system, their methodology resulted in less error (RMSE $=0.08^{\circ}, \mathrm{CC}=0.89$ to 0.99 ) across $5 \mathrm{DOF}$ compared to the two other methods [34]. The addition of a magnetometer in the analysis of data was also investigated using the EKF- and non-EKF-based fusion algorithm [15]. The latter produced the least difference between the two systems, irrespective of the speed of the movement and whether or not a magnetometer was included. In contrast, the EKF fusion algorithm resulted in the largest difference from the reference system, particularly for fast movements where magnetometer data was included $\left(7.37^{\circ} \pm 4.60\right.$ to $\left.11.91^{\circ} \pm 6.27\right)$ [15]. The level of customisation to achieve these results is summarised in Table 4 .

One study compared the difference between YEI Technology (YEI technology, Portsmouth, $\mathrm{OH}$ ) wearable sensors and Vicon during three customised calibration methods for the elbow, which resulted in RMSEs that ranged from 3.1 to $7.6^{\circ}$ [69]. 


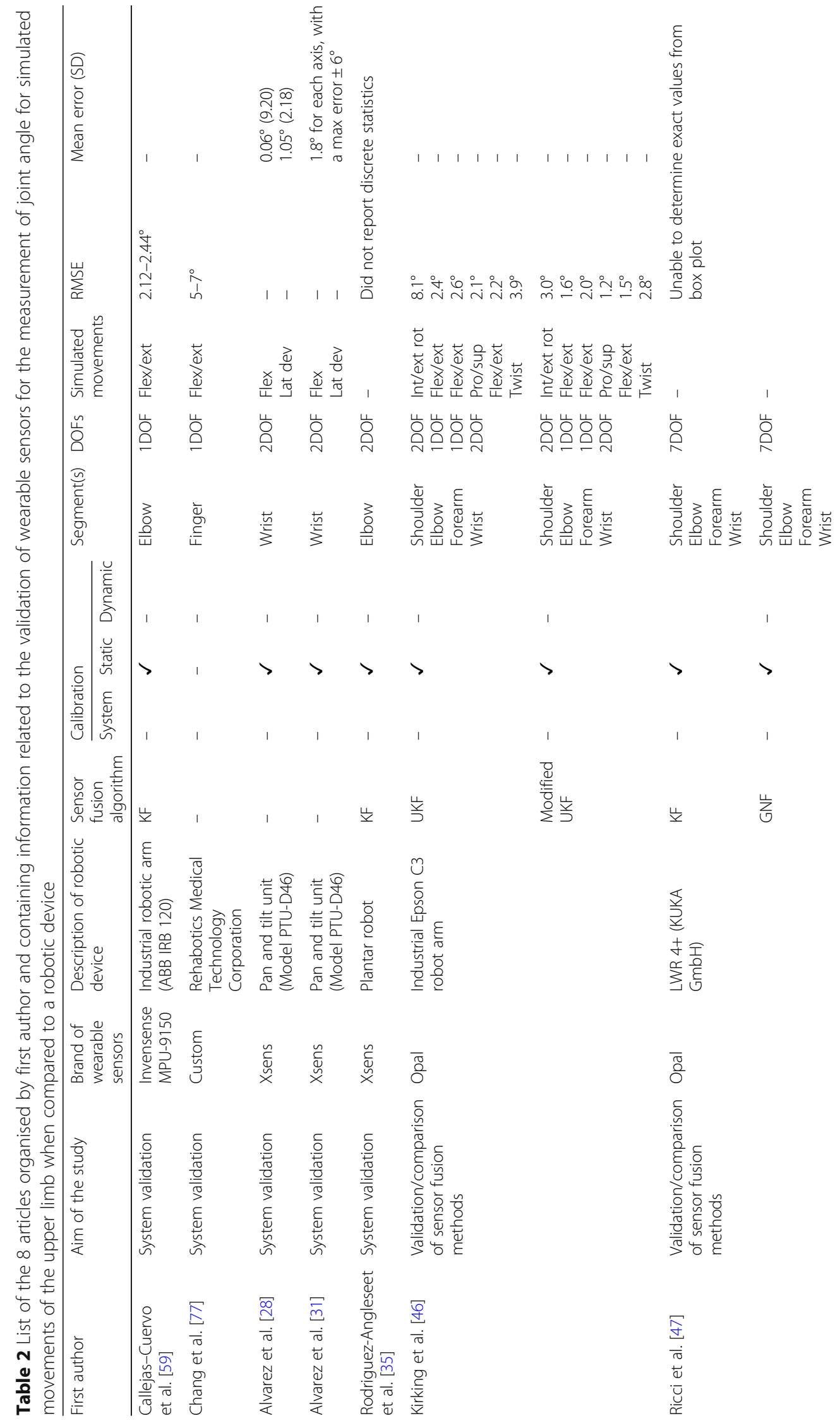


Walmsley et al. Sports Medicine - Open

(2018) 4:53

Page 11 of 22

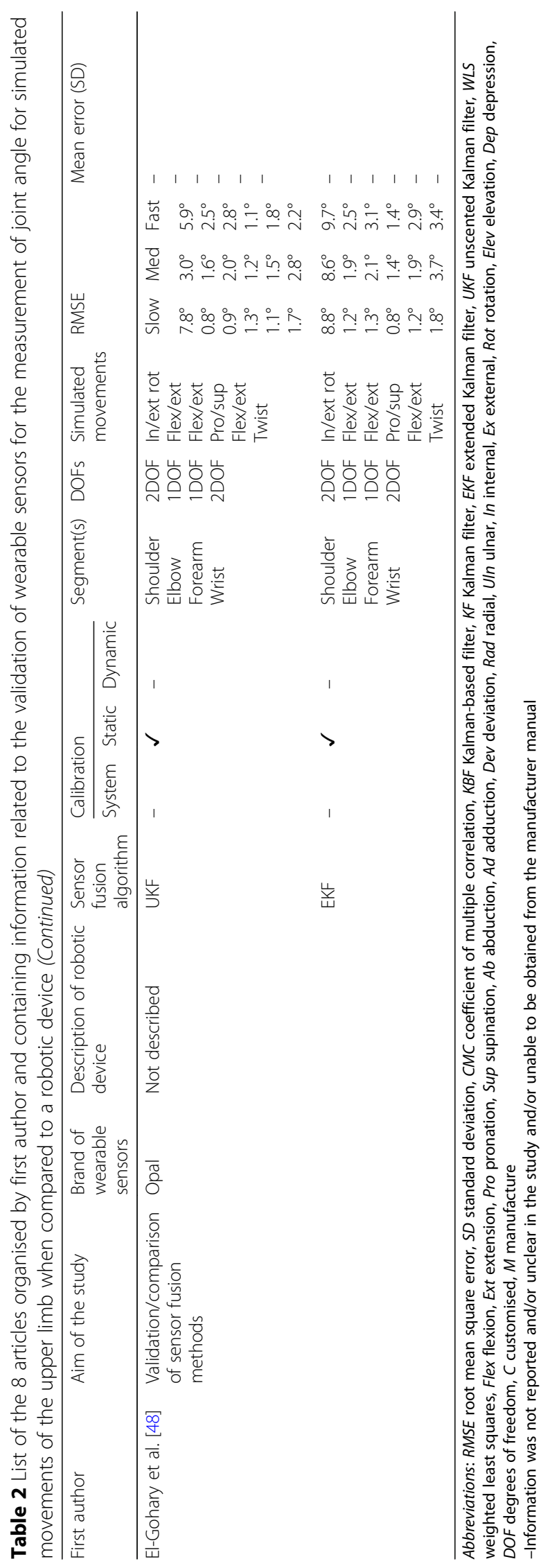




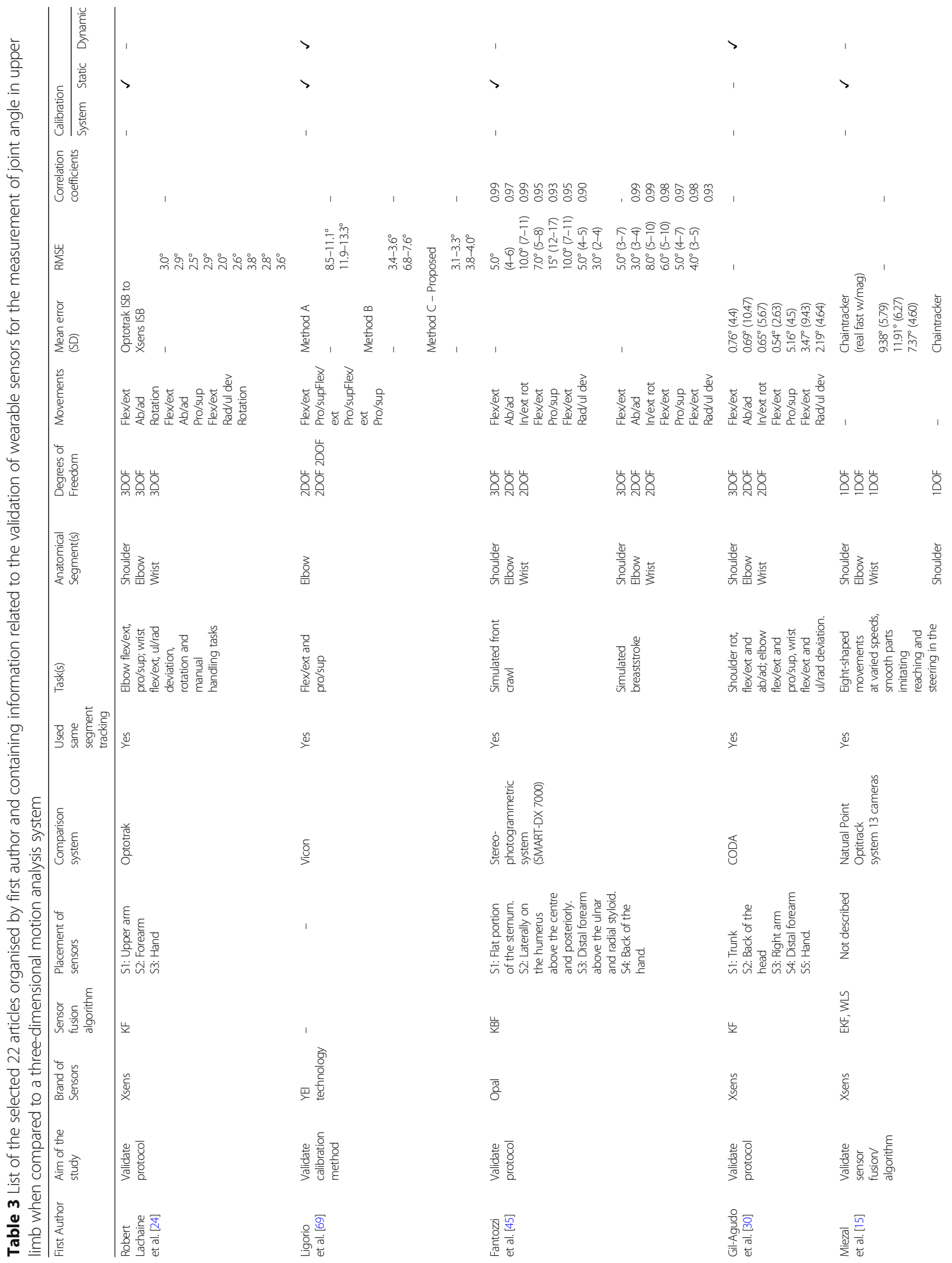




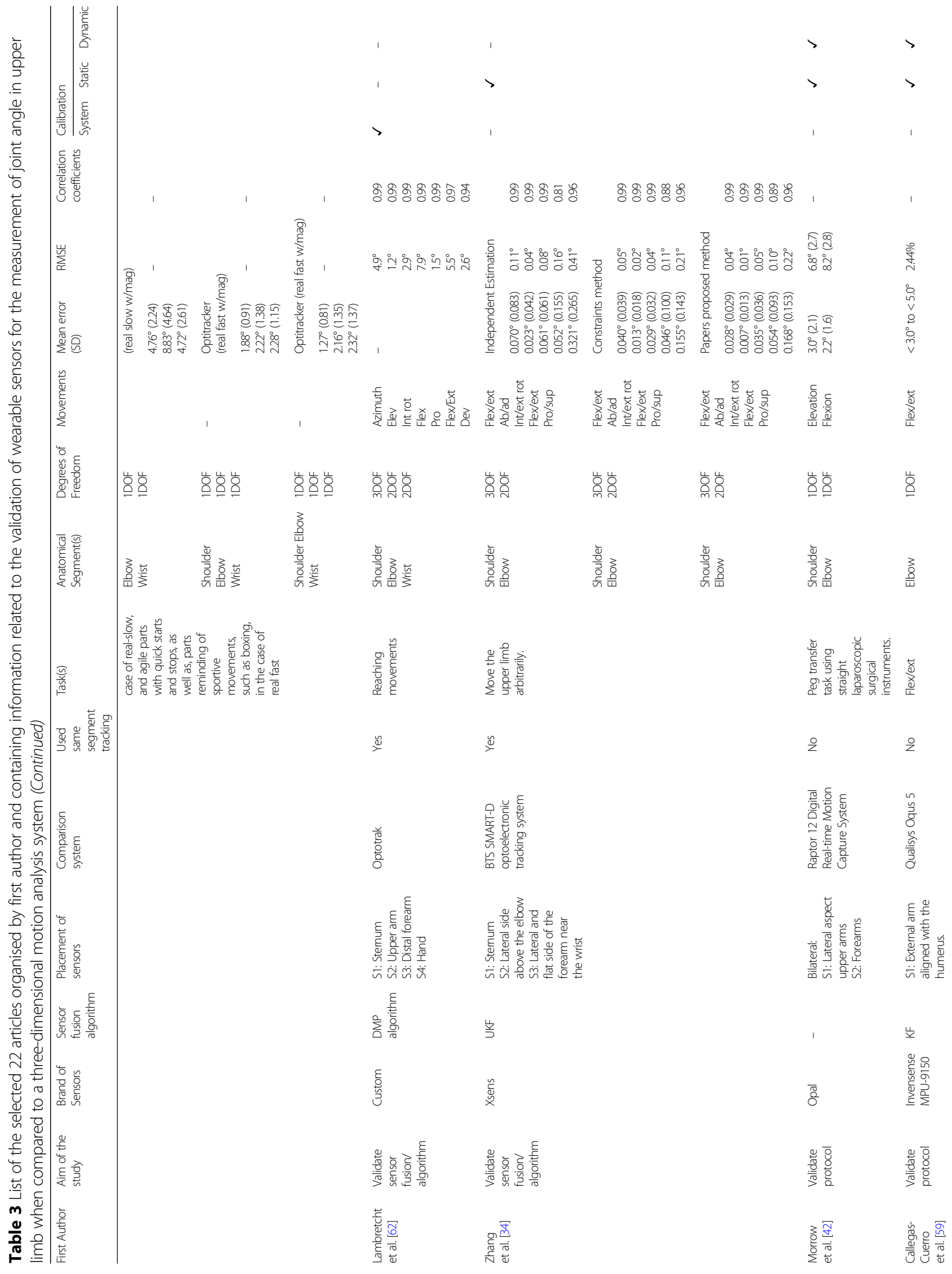




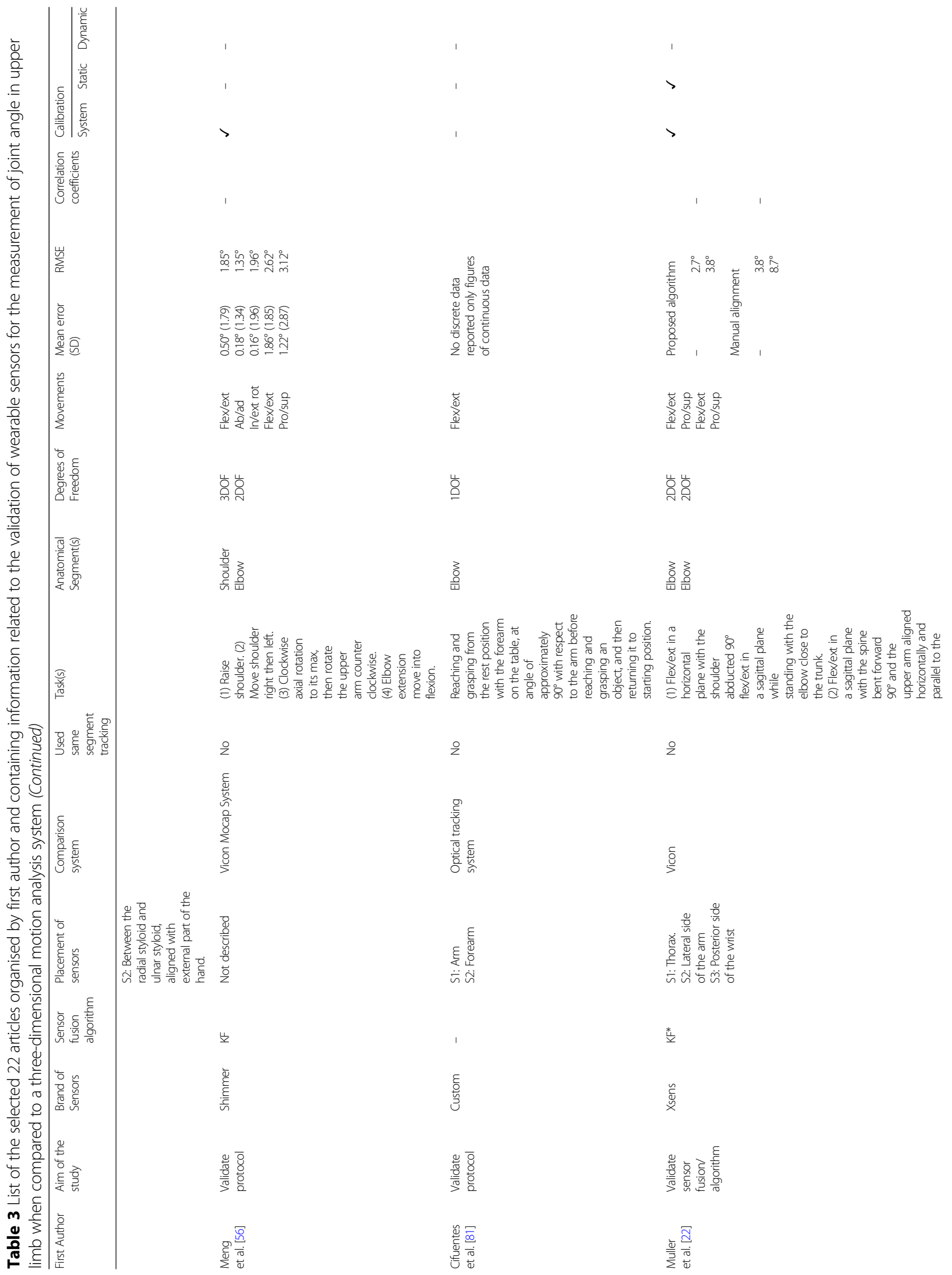




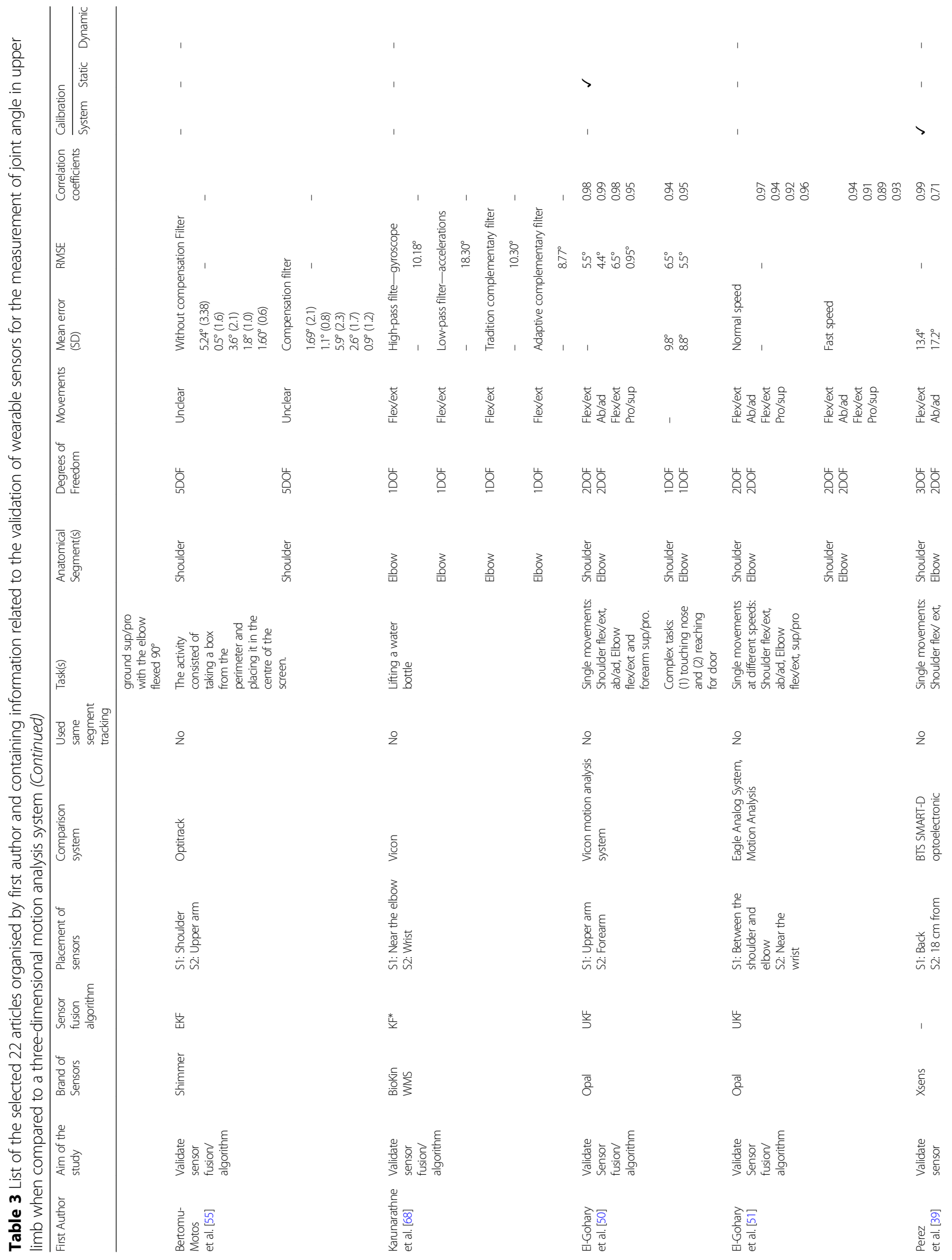




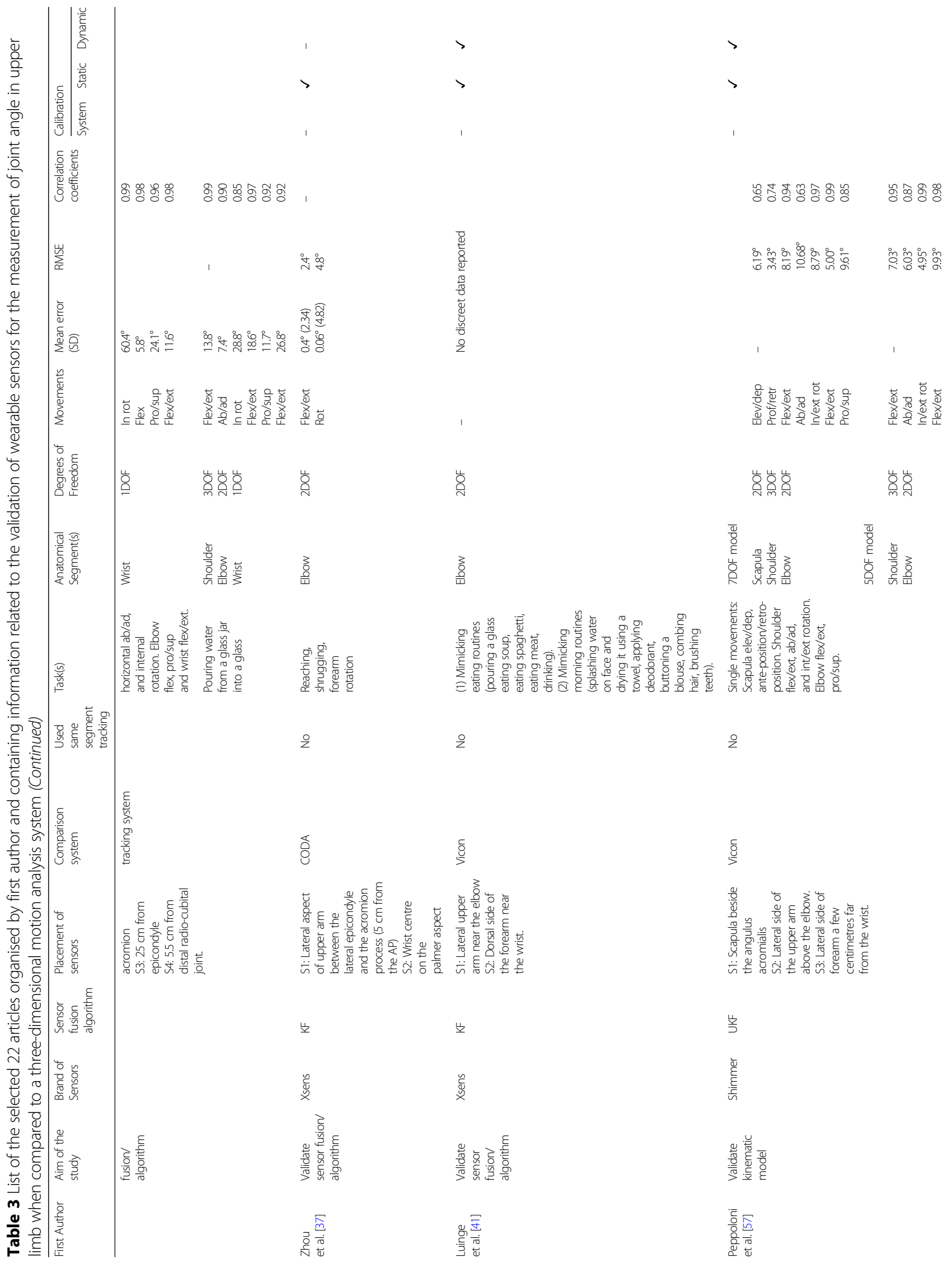




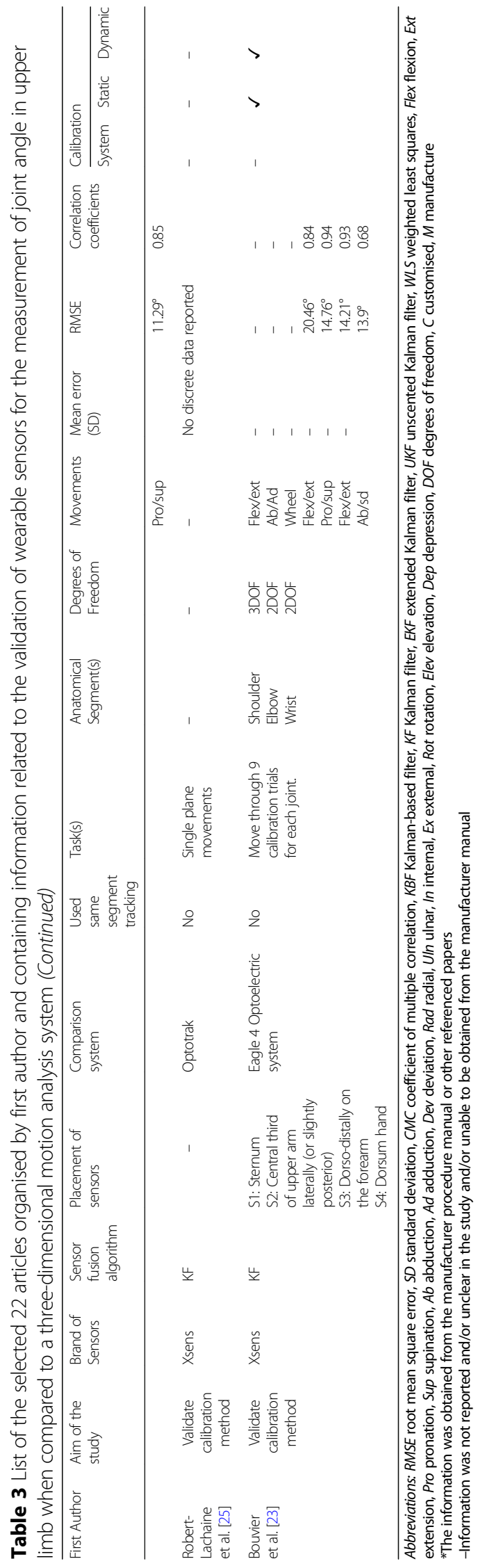


Table 4 Summary of the software customisation reported by the authors for validation studies that used the same segment tracking

\begin{tabular}{|c|c|c|c|c|c|}
\hline \multirow[t]{2}{*}{ First author } & \multirow[t]{2}{*}{ Sensor hardware } & \multicolumn{4}{|l|}{ Software } \\
\hline & & Sensor fusion algorithm & Calibration & $\begin{array}{l}\text { Anatomical segment } \\
\text { definition }\end{array}$ & $\begin{array}{l}\text { Kinematic } \\
\text { calculation }\end{array}$ \\
\hline Robert Lachaine et al. [24] & Commercial-Xsens MVN & Manufacturer & Manufacturer & Custom & Custom \\
\hline Ligorio et al. [69] & Commercial_YEI Technology & Custom & Custom & Custom & Custom \\
\hline Fantozzi et al. [45] & Commercial_ADPM Opal & Custom & Custom & Custom & Custom \\
\hline Gil-Agudo et al. [30] & Commercial—Xsens MTx & Custom & Custom & Custom & Custom \\
\hline Miezal et al. [15] & Commercial_Xsens & Did not report & Did not report & Custom & Custom \\
\hline Lambretcht et al. [62] & Commercial_InvenSense MPU9150 chip & Custom & Custom & Custom & Custom \\
\hline Zhang et al. [34] & Commercial—Xsens MTx & Custom & Manufacturer & Custom & Custom \\
\hline
\end{tabular}

\section{Reliability}

Adequate to excellent agreement was reported for $2 \mathrm{DOF}$ at the shoulder (ICC 0.68-0.81) and poor to moderate agreement for the 2DOF at the elbow (ICC 0.16-0.83). The wrist demonstrated the highest overall agreement with ICC values ranging from 0.65 to 0.89 for 2 DOF [73].

\section{Risk of Bias}

The sample sizes of the included studies were mostly inadequate, with $30 \%$ including single participants (Table 1). Twenty-eight percent of the included studies were conference papers, providing limited information.

\section{Discussion}

This systematic review described the characteristics of wearable sensors that have been applied in research and clinical settings on the upper limb, the populations with whom they have been used with, and their established psychometric properties. The inclusion of 66 studies allowed for a comprehensive synthesis of information.

Similar to other systematic reviews on wearable sensors, commercial wearable sensors, as opposed to custom designed, were reported in most studies (83\%) [17]. One benefit for users of commercial wearable sensors is the user-friendly nature of the associated manufacturer guidelines and processing software, including in-built fusion algorithms and joint calculation methods. However, the studies that utilised commercial hardware often customised aspects of the software (i.e. fusion algorithm, calibration method, anatomical segment definition, and the kinematic calculation). Therefore, the validity and reliability of an entirely commercial system (hardware and software) for use in the upper limb remains unknown. Customisation impacts the clinical utility of the wearable sensor systems, especially if there are no support personnel with appropriate knowledge and expertise.

Of the studies reviewed, there was no consensus on the procedures to follow for using wearable sensors on the upper limb. The placement of the wearable sensors varied and, in some cases, was poorly described.
Manufacturer guidelines for placement of commercial wearable sensors were not referred to, which lead to apparent differences in placement for studies that utilised the same commercial brand. Multiple fusion algorithms were reported, with no clear outcome about which was best suited to a specific joint or movement. The level of customisation of fusion algorithms makes it difficult to compare between studies, and often, the specifics of the algorithm were not readily available, limiting replication. Similar inconsistencies and a lack of consensus were reported in other systematic reviews investigating use of wearable sensors [16, 87]. Without clear guidelines, measurement error can be introduced and/or exacerbated depending on the procedures followed.

The methods of calibration also varied between studies, with a static anatomical calibration the most commonly utilised method (typically adopting a neutral pose, standing with arms by the side and palms facing forward, as recommended by most manufacturers). Dynamic anatomical calibration was often customised to suit the needs of the study and the joint being measured. For example, dynamic anatomical calibration of the elbow varied from repetitions of flexion and extension at various speeds [59], to the rapid movement of the arm from $45^{\circ}$ to neutral [42]. Details of the dynamic anatomical calibrations were omitted in some studies, limiting replication. More pertinent for the calculation of joint kinematics is anatomical calibration as compared to system calibration, with the type of calibration (i.e. static or dynamic) and movements of the dynamic anatomical calibration, having a significant impact on the accuracy of wearable sensors [69].

Of the 66 studies included in this review, almost half (45\%) were validation studies with the remaining studies using wearable sensors as an outcome measure. Over one third (29\%) were conference proceedings in the field of engineering, thus limiting the amount of information available. The median sample size was 7.6 participants per study; only one study was considered to have an adequate sample size for the validation of a measurement 
tool as per the COSMIN guidelines [19]. The majority (78\%) of the results were obtained from healthy adults, with clinical populations $(12 \%)$ and those under the age of $18(1.5 \%)$ not well represented. Research investigating the use of wearable sensors to measure lower limb kinematics has demonstrated a level of accuracy with clinical populations and children. Errors $<4^{\circ}$ were reported for elderly individuals with hemiparesis [88] and RMSEs between 4.6 and $8.8^{\circ}$ for children with spastic cerebral palsy [10]. There is potential for wearable sensors to be applied to the upper limb of these populations; however, more research is required to determine the optimal procedures prior to implementation in clinical practice.

The validity and reliability of wearable sensors when applied to the upper limb has not been clearly described to date. When compared to a robotic device, the commercial wearable sensors with customised software recorded errors below McGinley's [7] suggested 5.0 threshold. Less than $3.9^{\circ}$ was reported for replica/simulated movements of the wrist in 3 DOF $[28,46,48,56],<3.1^{\circ}$ for 2 DOF at the elbow $[46,48,56]$, and $<2.5^{\circ}$ for $1 \mathrm{DOF}$ (flexion/extension) at the shoulder [48]. Shoulder internal and external rotation resulted in the largest error $\left(3.0-9.7^{\circ}\right)$ [48], and therefore, results for this movement should be interpreted with caution.

The next section will discuss 'in vivo' studies with 3DMA as a pseudo gold standard. Studies that made a direct comparison between the wearable sensors and 3DMA system (i.e. used the same segment tracking) demonstrated differences that exceeded the suggested $5.0^{\circ}$ threshold, with up to $15.0^{\circ}$ difference reported for the elbow. However, depending on the software specifications and level of customisation, a difference of $<0.11^{\circ}$ (3DOF shoulder), $<0.41^{\circ}$ (2DOF elbow), and $<2.6$ (2DOF wrist) was achievable. The range in difference observed between the two systems is indicative that wearable sensors are still largely in a 'developmental phase' for the measurement of joint angle in the upper limb.

Consistent with prior findings, error values were unique to the joint and movement tasks being measured. Most of the tasks involved movements in multiple planes (i.e. reaching tasks), which resulted in more error compared to studies that assessed isolated movement in a single plane (i.e. flexion and extension). Measuring multiple planes of movement poses a further challenge to motion analysis and needs careful consideration when interpreting the results [89].

\section{Limitations}

Due to the heterogeneity in the reported studies, a meta-analysis was not appropriate given the variance in sample sizes, movement tasks, different procedures, and statistical analyses used. It was also not possible to apply a standard assessment of quality and bias due to the diversity of the studies. The inclusion of small samples (30\% single participant) is a potential threat to validity, with single participant analysis insufficient to support robustness and generalisation of the evidence. The inclusion of conference papers (28\%) meant that many papers provided limited detail on the proposed system and validation results. Small sample sizes and the inclusion of mostly healthy adults means the results of this review cannot be generalised to wider clinical populations. In addition, studies that utilised different segment tracking (i.e. 3DMA markers were not mounted on the wearable sensor) were not further analysed as it was not possible to delineate between the sources of error.

\section{Conclusion}

Wearable sensors have become smaller, more user-friendly, and increasingly accurate. The evidence presented suggests that wearable sensors have great potential to bridge the gap between laboratory-based systems and the goniometer for the measurement of upper limb joint angle during dynamic movement. A level of acceptable accuracy was demonstrated for the measurement of elbow and wrist flexion/extension when compared to a robotic device. Error was influenced by the fusion algorithm and method of joint calculation, which required customisation to achieve errors < $2.9^{\circ}$ from known angles on a robotic device. Higher error margins were observed in vivo when compared to a 3DMA system, but $<5^{\circ}$ was achievable with a high level of customisation. The additional level of customisation that was often required to achieve results with minimal error is particularly relevant to clinicians with limited technical support, and critically, when using a system 'off the shelf', the expected level of accuracy may not be comparable to the findings reported in this review.

With this technology rapidly evolving, future research should establish standardised protocol/guidelines, and subsequent reliability and validity for use in the upper limb, and in various clinical populations. Direct comparisons with the gold standard (i.e. same segment tracking) is needed to produce results that are most meaningful. We recommend and encourage the use of wearable sensors for the measurement of flexion/extension in the wrist and elbow; however, this should be combined with outcome measures that have demonstrated reliability and validity in the intended population.

\footnotetext{
Abbreviations

3DMA: Three-dimensional motion analysis; Ab: Abduction; Acc: Acceleration; Ad: Adduction; C: Customised; CMC: Coefficient of multiple correlations; Con: Conference paper; Dep: Depression; DOF: Degrees of freedom; DS: Double sided; EKF: Extended Kalman filter; Elev: Elevation; Ext rot: External rotation; Ext: Extension; Flex: Flexion; Full: Full text; Gyr: Gyroscope; ICC: Intraclass correlation coefficient; Int rot: Internal rotation; KBF: Kalman-based filter; KF: Kalman filter; M: Manufacturer; Mag: Magnetometer; PD: Parkinson's disease; Pro: Pronation; Rad dev: Radial deviation; RMSE: Root mean square error; ROM: Range of motion; SCl: Spinal cord injury; SD: Standard deviation; Sup: Supination; UKF: Unscented Kalman filter; Uln dev: Ulnar deviation
} 


\section{Acknowledgements}

This research was completed with financial support from the Australian Government Research Training Program Scholarship and the Perth Children's Hospital Foundation. The authors would like to acknowledge the support of Curtin University: the School of Occupational Therapy, Social Work and Speech Pathology, the School of Physiotherapy and Sport Science, and the Faculty of Health Science's librarian, Diana Blackwood. Further acknowledgement is extended to the Australian Catholic University and Centre for Research Excellence in Cerebral Palsy.

\section{Funding}

The authors wish to thank the School of Occupational Therapy, Social Work and Speech Pathology at Curtin University who provided funding.

\section{Availability of Data and Materials}

Data presented in this systematic review is available in the associated studies, and references are provided.

\section{Authors' Contributions}

All authors read and approved the final manuscript.

\section{Authors' information}

Not applicable

\section{Ethics Approval and Consent to Participate}

Ethical approval was not required for this systematic review.

\section{Consent for Publication}

Not applicable as this manuscript does not include any individual person's data.

\section{Competing Interests}

The authors Corrin Walmsley, Sian Williams, Tiffany Grisbrook, Catherine Elliott, Christine Imms, and Amity Campbell declare that they have no competing interests.

\section{Publisher's Note}

Springer Nature remains neutral with regard to jurisdictional claims in published maps and institutional affiliations.

\section{Author details}

'School of Occupational Therapy, Social Work and Speech Pathology, Curtin University, Perth, WA 6027, Australia. ${ }^{2}$ School of Physiotherapy and Exercise Science, Curtin University, Perth, WA 6027, Australia. ${ }^{3}$ Department of Surgery, University of Auckland, Auckland 1010, New Zealand. ${ }^{4}$ Kids Rehab WA, Perth Children's Hospital, Perth, WA 6008, Australia. ${ }^{5}$ Centre for Disability and Development Research, School of Allied Health, Australian Catholic University, Melbourne, VIC 3065, Australia.

\section{Received: 31 July 2018 Accepted: 24 October 2018}

\section{Published online: 29 November 2018}

\section{References}

1. Bonato P. Advances in wearable technology and applications in physical medicine and rehabilitation. J of NeuroEng \& Rehab. 2005;2(2):1-4. https:// doi.org/10.1186/1743-0003-2-2.

2. dos Santos CM, Ferreira G, Malacco PL, GFS M, Felicio DC. Intra and inter examiner reliability and measurement error of goniometer and digital inclinometer use. Rev Bras Med Esporte. 2012;18(1). https://doi.org/10.1590/ S1517-86922012000100008.

3. Chapleau J, Canet F, Petit Y, Laflamme G, Rouleau D. Validity of goniometric elbow measurements. Clin Orthop Relat Res. 2011;469:3134-40. https://doi. org/10.1007/s11999-011-1986-8.

4. Muir SW, Correa CL, Beaupre L. Evaluating change in clinical status: reliability and measures of agreement for the assessment of glenohumeral range of motion. N Am J Sports Phys Ther. 2010;5(3):98-110. http://www.ncbi.nlm. nih.gov.

5. Gajdosik RL, Bohannon RW. Clinical measurement of range of motion: review of goniometry emphasizing reliability and validity. Phys Ther J. 1987; 16:1867-72. https://doi.org/10.1016/j.kine.2018.01.011.
6. Herrero P, Carrera P, Garcia E, Gomez-Trullen EM, Olivian-Blazquez B. Reliability of goniometric measurements in children with cerebral palsy: a comparative analysis of universal goniometer and electronic inclinometer: a pilot study. BMC Musculoskelet Disord. 2011;12:155. https://doi.org/10.1186/1471-2474-12-155.

7. McGinley $J \mathrm{~L}$, Baker R, Wolfe R, Morris ME. The reliability of three-dimensional kinematic gait measurements: a systematic review. Gait \& Posture. 2009;29: 360-9. https://doi.org/10.1016/j.gaitpost.2008.09.003.

8. Rau G, Disselhorst-Klug C, Schmidt R. Movement biomechanics goes upwards: from the leg to the arm. J Biomech. 2000;33(10):1207-16. https://doi.org/10.1013/S0021-9290(00)00062-2.

9. Reid S, Elliott C, Alderson J, Lloyd D, Elliott B. Repeatability of upper limb kinematics for children with and without cerebral palsy. Gait \& Posture. 2010;32(1):10-7. https://doi.org/10.1016/j.gaitpost.2010.02.015.

10. van den Noort JC, Ferrari A, Cutti AG, Becher JG, Harlaar J. Gait analysis in children with cerebral palsy via inertial and magnetic sensors. Med Biol Eng Comput. 2013;51:377-86. https://doi.org/10.1007/s11517-012-1006-5.

11. Coley B, Jolles BM, Farron A, Bourgeois A, Nussbaumer F, Pichonnaz C, et al. Outcome evaluation in shoulder surgery using 3D kinematics sensors. Gait \& Posture. 2007;25(4):523-32. https://doi.org/10.1016/j.gaitpost.2006.06.016.

12. Filippeschi A, Schmitz N, Miezal M, Bleser G, Ruffaldi E, Stricker D. Survey of motion tracking methods based on inertial sensors: a focus on upper limb human movement. Sensors. 2017;17(6):1257. https://doi.org/10.3390/s17061257.

13. de Vries WHK, Veeger HEJ, Cutti AG, Baten C, van der Helm FCT. Functionally interpretable local coordinate systems for the upper extremity using inertial \& magnetic measurement systems. J Biomech. 2010;43(10): 1983-8. https://doi.org/10.1016/j.jbiomech.2010.03.007.

14. Lopez-Nava I, Munoz-Melendez A. Wearable inertial sensors for human motion analysis: a review. IEEE Sensors J. 2016;16(22):1558-748. https://doi. org/10.1109/JSEN.2016.2609392.

15. Miezal M, Taetz B, Bleser G. On inertial body tracking in the presence of model calibration errors. Sensors. 2016;16(7):1132-66. https://doi.org/10. 3390/s16071132.

16. de Magalhaes FA, Vannozzi G, Gatta G, Fantozzi S. Wearable inertial sensors in swimming motion analysis: a systematic review. J of Sports Sci. 2014; 33(7):732-45. https://doi.org/10.1080/02640414.2014.962574.

17. Cuesta-Vargas Al, Galán-Mercant A, Williams WM. The use of inertial sensors system for human motion analysis. Phys Ther Rev. 2010;15(6):462-73. https://doi.org/10.1179/1743288X11Y.0000000006.

18. Fong $D, C$ Chan $Y$. The use of wearable inertial motion sensors in human lower limb biomechanics studies: a systematic review. Sensors. 2010;10(12): 11556-65. https://doi.org/10.3390/s101211556.

19. Mokkink LB, Terwee CB, Patrick DL, Alonso J, Stratford PW, Knol DL, et al. The COSMIN study reached international consensus on taxonomy, terminology, and definitions of measurement properties for health-related patient-reported outcomes. J of Clin Epidemiol. 2010;63:737-45. https://doi. org/10.1016/j.jclinepi.2010.02.006.

20. Moher D, Liberati A, Tetzlaff J, Altman DG. Preferred reporting items for systematic reviews and meta-analyses: the PRISMA statement. BMJ. 2009; 339. https://doi.org/10.1136/bmj.b2535.

21. Portney L, Watkins M. Foundations of clinical research. Trenton: Pearson Education Inc; 2009

22. Muller P, Begin M-A, Schauer T, Seel T. Alignment-free, self-calibrating elbow angles measurement using inertial sensors. J of Biomed and health Infor. 2017;21(2):312-9. https://doi.org/10.1109/JBHI.2016.2639537.

23. Bouvier B, Duprey S, Claudon L, Dumas R, Savescu A. Upper limb kinematics using inertial and magnetic sensors: comparison of sensor-to-segment calibrations. Sensors. 2015;15(8):18813-33. https://doi.org/10.3390/s150818813.

24. Robert-Lachaine X, Mecheri H, Larue C, Plamondon A. Validation of inertial measurement units with an optoelectronic system for whole-body motion analysis. Med Biol Eng Comput. 2017;55:609-19. https://doi.org/10.1007/ s11517-016-1537-2.

25. Robert-Lachaine $\mathrm{X}$, Mecheri $\mathrm{H}$, Larue C, Plamondon A. Accuracy and repeatability of single-pose calibration of inertial measurement units for whole-body motion analysis. Gait \& Posture. 2017;54:80-6. https://doi.org/ 10.1016/j.gaitpost.2017.02.029.

26. Eckardt $F$, Witte K. Kinematic analysis of the rider according to different skill levels in sitting trot and canter. J Equine Vet Sci. 2016;39:51-7. https://doi. org/10.1016/j.jevs.2015.07.022.

27. Eckardt F, Munz A, Witte K. Application of a full body inertial measurement system in dressage riding. J Equine Vet Sci. 2014;34(11-12):1294-9. https:// doi.org/10.1016/j.jevs.2014.09.009. 
28. Alvarez D, Alvarez JC, Gonzalez RC, Lopez AM. Upper limb joint angle measurement in occupational health. Comp Methods in Biomech and Biomed Engin. 2016;19(2):159-70. https://doi.org/10.1080/10255842.2014. 997718.

29. Quinones-Uriostegui I, Bernal-Yescas F, Tovar-Sandoval JA, Vela-Pena E, Bourdon-Santoyo M, Perez-Sanpablo Al, editors. Biomechanical analysis of the propulsion of the manual wheelchair in patients with spinal cord injury. Brasilia: Pan American health care exchanges, PAHCE; 2014.

30. Gil-Agudo A, de los Reyes-Guzman A, Dimbwadyo-Terrer I, Penasco-Martin B, Bernal-Sahun A, Lopez-Monteagudo P, et al. A novel motion tracking system for evaluation of functional rehabilitation of the upper limbs. Neural Regen Res. 2013;8(19):1773-82. https://doi.org/10.3969/j.issn.1673-5374.2013.19.005.

31. Alvarez D, Alvarez JC, Gonzalez RC, Lopez AM, editors. Ambulatory human upper limb joint motion monitoring. Graz: IEEE Int Instrum and MeasTech Conference; 2012.

32. Bai L, Pepper MG, Yan Y, Spurgeon SK, Sakel M. Application of low cost inertial sensors to human motion analysis. Binjiang: IEEE Int Instrum and MeasTechnol Conference; 2011.

33. Bai L, Pepper MG, Yan Y, Spurgeon SK, Sakel M, Phillips M, editors. A multiparameter assessment tool for upper limb motion in neurorehabilitation. Graz: IEEE Int Instrum and MeasTechnol Conference; 2011

34. Zhang ZQ, Wong WC, Wu JK. Ubiquitous human upper-limb motion estimation using wearable sensors. IEEE Tran Inf Technol Biomed. 2011;15(4): 513-21. https://doi.org/10.1109/TITB.2011.2159122.

35. Rodriguez-Angeles A, Guzman-Gutierrez JL, Cruz-Villar C, editors. User wearable interface based on inertial sensors for unilateral master-slave robot teleoperation. Tuxtla: Int conference on electrical engineering, computing science and automatic control, CCE; 2010

36. Cutti AG, Giovanardi A, Rocchi L, Davalli A, Sacchetti R. Ambulatory measurement of shoulder and elbow kinematics through inertial and magnetic sensors. Med Biol Eng Comput. 2008;46(2):169-78. https://doi.org/ 10.1007/s11517-007-0296-5

37. Zhou H, Stone T, Hu H, Harris N. Use of multiple wearable inertial sensors in upper limb motion tracking. Med Eng Phys. 2008;30(1):123-33. https://doi. org/10.1016/j.medengphy.2006.11.010.

38. Zhou H, Hu H, Harris ND, Hammerton J. Applications of wearable inertial sensors in estimation of upper limb movements. Biomed Signal Process Control. 2006;1 (1):22-32. https://doi.org/10.1016/j.bspc.2006.03.001.

39. Perez R, Costa U, Torrent M, Solana J, Opisso E, Caceres C, et al. Upper limb portable motion analysis system based on inertial technology for neurorehabilitation purposes. Sensors. 2010;10(12):10733-51. https://doi.org/ 10.3390/s101210733.

40. Miguel-Andres I, Alonso-Rasgado T, Walmsley A, Watts AC. Effect of anconeus muscle blocking on elbow kinematics: electromyographic, inertial sensors and finite element study. Ann Biomed Eng. 2016:1-14. https://doi. org/10.1007/s10439-016-1715-2.

41. Luinge $\mathrm{HJ}$, Veltink PH, Baten CTM. Ambulatory measurement of arm orientation. J Biomech. 2007:40(1):78-85. https://doi.org/10.1016/j.jbiomech.2005.11.011.

42. Morrow M, Lowndes B, Fortune E, Kaufman KR, Hallbeck MS. Validation of inertial measurement units for upper body kinematics. J Appl Biomech. 2017;33(3):227-32. https://doi.org/10.1123/jab.2016-0120.

43. Rose M, Curtze C, O'Sullivan J, El-Gohary M, Crawford D, Friess D, et al. Wearable inertial sensors allow for quantitative assessment of shoulder and elbow kinematics in a cadaveric knee arthroscopy model. Arthroscopy: The J of Arthroscopic \& Related. 2017;33(12):2110-6. https://doi.org/10.1016/j. arthro.2017.06.042

44. Bertrand P, Reyes S, Newman D, editors. Pressure and kinematic in-suit sensors: assessing human-suit interaction for injury risk mitigation. Helena: IEEE aerospace conference proceedings; 2016.

45. Fantozzi S, Giovanardi A, Magalhaes FA, Di Michele R, Cortesi M, Gatta G. Assessment of three-dimensional joint kinematics of the upper limb during simulated swimming using wearable inertial-magnetic measurement units. Sports Sci. 2016;34(11):1073-80. https://doi.org/10.1080/02640414.2015. 1088659.

46. Kirking B, El-Gohary M, Kwon Y. The feasibility of shoulder motion tracking during activities of daily living using inertial measurement units. Gait \& Posture. 2016;49:47-53. https://doi.org/10.1016/j.gaitpost.2016.06.008

47. Ricci L, Taffoni F, Formica D. On the orientation error of IMU: investigating static and dynamic accuracy targeting human motion. PLoS One. 2016;11(9): 1-15. https://doi.org/10.1371/journal.pone.0161940.
48. El-Gohary M, McNames J. Human joint angle estimation with inertial sensors and validation with a robot arm. IEEE T. Biomed Eng. 2015;62(7):1759-67. https://doi.org/10.1109/tbme.2015.2403368.

49. Ricci L, Formica D, Tamilia E, Taffoni F, Sparaci L, Capirci O et al, editors. An experimental protocol for the definition of upper limb anatomical frames on children using magneto-inertial sensors. IEEE Engineering in Medicine and Biology Society Annual Conference; 2013:4903-4906. doi: 10.1109/ EMBC.2013.6610647.

50. El-Gohary M, McNames J. Shoulder and elbow joint angle tracking with inertial sensors. IEEE T Biomed Eng. 2012;59(9):2635-41. https://doi.org/10. 1109/tbme.2012.2208750.

51. El-Gohary M, Holmstrom L, Huisinga J, King E, McNames J, Horak F. Upper limb joint angle tracking with inertial sensors. Boston: Annual Int conference of the IEEE engineering in medicine and biology society, EMBS; 2011.

52. Mazomenos EB, Biswas D, Cranny A, Rajan A, Maharatna K, Achner J, et al. Detecting elementary arm movements by tracking upper limb joint angles with MARG sensors. IEEE J Biomed Health Info. 2016;20(4):1088-99. https:// doi.org/10.1109/jbhi.2015.2431472.

53. Tran TM, Vejarano G. Prediction of received signal strength from human joint angles in body area networks. Kauai: Int conference on computing, networking and communications, ICNC; 2016.

54. Daunoravicene K, Linkel A, Ziziene J, Griskevicius J, Juocevicius A, Raudonyte I, et al. Alternative method of upper extremity function assessment of stroke patients by angular kinematic parameters. J Mech Med Biol. 2017;17(5): 1750080-95. https://doi.org/10.1142/s0219519417500804.

55. Bertomeu-Motos A, Lledo LD, Diez JA, Catalan JM, Ezquerro S, Badesa FJ, et al. Estimation of human arm joints using two wireless sensors in robotic rehabilitation tasks. Sensors. 2015;15(12):30571-83. https://doi.org/10.3390/ s151229818.

56. Meng D, Vejarano G, editors. Development of a wireless sensor network for the measurement of human joint angles. Las Vegas: Int conference on connected vehicles and expo, ICCVE; 2013.

57. Peppoloni L, Filippeschi A, Ruffaldi E, Avizzano CA, editors. A novel 7 degrees of freedom model for upper limb kinematic reconstruction based on wearable sensors. Subotica: IEEE 11th IntSymposium on Intelligent Systems and Informatics, SISY; 2013.

58. Ruiz-Olaya AF, Callejas-Cuervo M, Lara-Herrera CN. Wearable low-cost inertial sensor-based electrogoniometer for measuring joint range of motion. DYNA. 2017;84(201):180-5. https://doi.org/10.15446/dyna.v84n201.59054.

59. Callejas-Cuervo M, Gutierrez RM, Hernandez Al. Joint amplitude MEMS based measurement platform for low cost and high accessibility telerehabilitation: elbow case study. J Bodyw Mov Ther. 2017;21(3):574-81. https://doi.org/10.1016/j.jbmt.2016.08.016.

60. Li J, Pan B, Jin T, Huang Z, Ye S, Wu J, et al. A single task assessment system of upper-limb motor function after stroke. Technol Health Care. 2016;24: 707-15. https://doi.org/10.3233/THC-161199.

61. Gao Y, Zhang L, Du M, Vai Ml, editors. Design of human motion detection based on the human body communication. Macao: IEEE annual Int Conference,TENCON; 2015.

62. Lambrecht JM, Kirsch RF. Miniature low-power inertial sensors: promising technology for implantable motion capture systems. IEEE T Neural Syst and Rehabili Eng. 2014;22(6):1138-47. https://doi.org/10.1109/tnsre.2014.2324825.

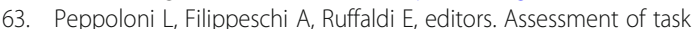
ergonomics with an upper limb wearable device. Palmero: 22nd Mediterranean conference on control and automation, MED; 2014.

64. Eom SH, Lee EH. A study on the operation of rehabilitation interfaces in active rehabilitation exercises for upper limb hemiplegic patients: interfaces for lateral and bilateral exercises. J Tech Health Care. 2016;24:607-23. https://doi.org/10.3233/THC-161188.

65. Roldan-Jimenez C, Cuesta-Vargas Al. Age-related changes analyzing shoulder kinematics by means of inertial sensors. Clin Biomech. 2016;37:706. https://doi.org/10.1016/j.clinbiomech.2016.06,004.

66. Roldán-Jiménez C, Cuesta-Vargas Al. Studying upper-limb kinematics using inertial sensors: a cross-sectional study. BMC Res Notes. 2015;8(1):1-10. https://doi.org/10.1186/s13104-015-1517-x.

67. Nguyen N, Pham T, Mahani T, Pathirana PN, Babazadeh S, Ling F, et al., editors. Effects of wrist kinematic coupling movements during dartthrower's motion. Rajpura: Int conference on wireless networks and embedded systems; 2017.

68. Karunarathne MS, Ekanayake SW, Pathirana PN, editors. An adaptive complementary filter for inertial sensor based data fusion to track upper 
body motion. Colombo: Int conference on information and automation for sustainability, ICIAFS; 2014

69. Ligorio G, Zanotto D, Sabatini AM, Agrawal SK. A novel functional calibration method for real-time elbow joint angles estimation with magnetic-inertial sensors. J Biomech. 2017;54:106-10. https://doi.org/10. 1016/j.jbiomech.2017.01.024.

70. Vignais N, Bernard F, Touvenot G, Sagot JC. Physical risk factors identification based on body sensor network combined to videotaping Appl Ergon. 2017;65:410-7. https://doi.org/10.1016/j.apergo.2017.05.003.

71. Chen PJ, Du YC, Shih CB, Yang LC, Lin HT, Fan SC, editors. Development of an upper limb rehabilitation system using inertial movement units and kinect device. Shenzhen: Int conference on advanced materials for science and engineering; 2016.

72. Matsumoto H, Ueki M, Uehara K, Noma H, Nozawa N, Osaki M, et al. Comparison of healthcare workers transferring patients using either conventional or robotic wheelchairs: kinematic, electromyographic, and electrocardiographic analyses. J Healthc Eng. 2016. https://doi.org/10.1155/2016/5963432

73. Schiefer C, Kraus T, Ellegast RP, Ochsmann E. A technical support tool for joint range of motion determination in functional diagnostics: an inter-rater study. J Occup med and Toxicol. 2015;10(1):16. https://doi.org/10.1186/ s12995-015-0058-5.

74. Balbinot A, de Freitas JCR, Correa DS. Use of inertial sensors as devices for upper limb motor monitoring exercises for motor rehabilitation. Health Tech. 2015;5(2):91-102. https://doi.org/10.1007/s12553-015-0110-6.

75. Huang S, Luo C, Ye S, Liu F, Xie B, Wang C, et al. Motor impairment evaluation for upper limb in stroke patients on the basis of a microsensor. Int J Rehabil Res. 2012;35(2):161-9. https://doi.org/10.1097/MRR. 0b013e328353053a.

76. Salman M, Qaisar S, Qamar AM. Classification and legality analysis of bowling action in the game of cricket. Data Min and Knowl Disc. 2017:1-29. https://doi.org/10.1007/s10618-017-0511-4

77. Chang HT, Cheng LW, Chang JY. Development of IMU-based angle measurement system for finger rehabilitation. Nanjing: 23 rd Int Conference on Mechatronics and Machine Vision in Practice (M2vip); 2016. p. 196-201.

78. Borbely BJ, Tihanyi A, Szolgay P, editors. A measurement system for wrist movements in biomedical applications. Trondheim: European conference on circuit theory and design, ECCTD; 2015.

79. Kumar Y, Yen SC, Tay A, Lee W, Gao F, Zhao Z, et al. Wireless wearable range-of-motion sensor system for upper and lower extremity joints: a validation study. Healthc Tech Letters. 2015;2(1):12-7. https://doi.org/10. 1049/htl.2014.0100.

80. Lee WW, Yen SC, Tay A, Zhao ZY, Xu TM, Ling KKM, et al. A smartphone-centric system for the range of motion assessment in stroke patients. IEEE J Biomed Health Inform. 2014;18(6):1839-47. https://doi.org/10.1109/jbhi.2014.2301449.

81. Cifuentes C, Braidot A, Rodriguez L, Frisoli M, Santiago A, Frizera A, editors. Development of a wearable zigbee sensor system for upper limb rehabilitation robotics. Rome: 4th IEEE Int conference on biomedical robotics and biomechatronics; 2012

82. Kanjanapas $K$, Wang Y, Zhang W, Whittingham L, Tomizuka M, editors. A human motion capture system based on inertial sensing and a complementary filter. Standord: ASME dynamic systems and control conference, DSCC: 2013.

83. Zhang Z, LWC W, Wu JK, editors. 3D upper limb motion modeling and estimation using wearable micro-sensors. Singapore: Int conference on body sensor networks, BSN; 2010.

84. Lin HC, Chiang SY, Lee K, Kan YC. An activity recognition model using inertial sensor nodes in a wireless sensor network for frozen shoulder rehabilitation exercises. Sensors. 2015;15(1):2181-204. https://doi.org/10. 3390/s150102181.

85. El-Gohary M, Pearson S, McNames J. Joint angle tracking with inertial sensors. Vancouver: Annual Int Conference of the IEEE Engineering in Medicine and Biology Society Conference; 2008. p. 1068-71.

86. Hyde RA, Ketteringham LP, Neild SA, Jones RJS. Estimation of upper-limb orientation based on accelerometer and gyroscope measurements. IEEE TBiomed Eng. 2008;55(2):746-54. https://doi.org/10.1109/TBME.2007.912647.

87. Mooney R, Corley G, Godfrey A, Quinlan L, O'Laighin G. Inertial sensor technology for elite swimming performance analysis: a systematic review. Sensors. 2015;16:18. https://doi.org/10.3390/s16010018.
88. Watanabe K, Morishita H, Mori T, Sato T, editors. A prototype of index-finger PIP joint motion amplifier for assisting patients with impaired hand mobility. Roma: IEEE Int Conference on Robotics and Automation; 2007. p. 10-4.

89. Charry E, Umer M, Taylor S, editors. Design and validation of an ambulatory inertial system for 3-D measurements of low back movements. Adelaide: Int conference on Intellegent sensors, sensor networks and Informationa processing.

\section{Submit your manuscript to a SpringerOpen ${ }^{\circ}$ journal and benefit from:}

- Convenient online submission

- Rigorous peer review

- Open access: articles freely available online

- High visibility within the field

- Retaining the copyright to your article

Submit your next manuscript at $\boldsymbol{\nabla}$ springeropen.com 